\title{
Inovasi Pewarnaan dan Kreativitas Pengolahan Limbah Pertenunan Tradisional Santa Maria Boro
}

\author{
Retno Ika Sundari $^{\# 1}$, Yosephine Flori Setiarini*2 \\ ${ }^{\#}$ Akuntansi, Universitas Kristen Duta Wacana, Jl. Dr. Wahidin Sudirohusodo No.5-25, Kotabaru, Kec. \\ Gondokusuman, Kota Yogyakarta, Daerah Istimewa Yogyakarta 55224, Yogyakarta \\ ${ }^{1}$ retnosundari@staff.ukdw.ac.id \\ *Desain Busana, Akademi Kesejahteraan Sosial AKK Yogyakarta, Jl. Nitikan Baru No.69, Sorosutan, Kec. \\ Umbulharjo, Kota Yogyakarta, Daerah Istimewa Yogyakarta 55162, Yogyakarta \\ 2florisetiarini@gmail.com
}

\begin{abstract}
Abstrak-Abstrak-Tenun lurik merupakan salah satu hasil budaya bangsa Indonesia yang perlu dipertahankan, salah satunya Pertenunan Santa Maria Boro. Pertenunan Santa Maria Boro yang berada di Kecamatan Banjarasri, Kalibawang Kabupaten Kulonprogo telah berdiri sejak tahun 1927 mampu membuktikan eksistensi pertenunan tradisional di tengah globalisasi. Selama ini, produksi yang sudah dihasilkan diantaranya adalah selimut, handuk, kain pel, serbet, sarung, sprei, sarung bantal, lap tangan, lap piring, serta baju imam. Eksistensi dan kualitas hasil produksi pertenunan tradisonal memerlukan sentuhan inovasi untuk memenangkan keunggulan kompetitif. Salah satu usaha dalam memenangkan keunggulan kompetitif adalah dengan meningkatkan valueadded kain tenun tradisional. Upaya ini dilakukan oleh tim pengabdi melalui metode kreativitas pewarnaan dan kreasi Teknik hias pada kain yang dihasilkan Pertenunan Santa Maria Boro berbasis Alat Tenun Bukan Mesin (ATBM). Pewarnaan dilakukan dengan menggunakan kombinasi dari warna dasar dan kombinasi motif melalui Teknik ikat dan Teknik jepit. Selain itu program ini juga berupaya mengelola limbah tenun yang berupa "kawul" untuk dijadikan gantungan kunci. Luaran dari program pengabdian ini adalah prototipe inovasi pewarnaan dengan Teknik ikat dan jepit. Program ini tidak hanya berhasil dalam upaya pelestarian hasil budaya bangsa Indonesia, namun juga mendukung program pemerintah untuk memajukan program Ekonomi Kreatif.
\end{abstract}

Katakunci: inovasi, kreativitas, ekonomi kreatif, ATBM, Santa Maria Boro.

Abstract-Lurik weaving is one of the cultural products in Indonesia that needs to be preserved. Santa Maria Boro Weaving which is located in Banjarasri District, Kalibawang, Kulonprogo Regency has been established since 1927 and is able to prove its existence as the traditional weaving industry in the globalization era. So far, some of the products that have been produced are blankets, towels, mops, napkins, sarongs, bed linen, pillowcases, hand towels, dish towels, and priest's clothes. The existence and the quality of the traditional woven products requires a special touch of innovation to win a competitive advantage. One of the efforts to win a competitive advantage is to increase the value-added of the traditional woven fabrics. This effort was done by the team using the creative method of colouring and decorative techniques creations on the fabrics produced by Santa Maria Boro weaving industry which are based on Non-Machine Weaving Equipment (NMWE). The colouring is done by using a combination of basic colours and a combination of motifs using the tying and the pinning techniques. Moreover, this program also managed the weaving waste in the form of "kawul" which is created as key chains. The output of this service program was a prototype of colouring innovation using the tying and pinning techniques. This program was not only successful in preserving the cultural products in Indonesia but also supported the government's programs to advance the Creative Economy program.

Keywords: innovation, creativity, creative economy, NMWE, Santa Maria Boro

\section{Pendahuluan}

Tenun lurik merupakan salah satu budaya bangsa yang perlu diprertahankan. Pelestarian ini akan membuat tenun lurik mampu bersaing di tengah persaingan global. Sejak akhir pemerintahan Susilo Bambang Yudhoyono dilanjutkan dengan pemerintahan Joko Widodo perdagangan nasional mengusung tema Ekonomi kreatif [1] yang menitikberatkan pada kemampuan kreatifitas terhadap barang dan jasa agar memunyai nilai tambah yang tinggi 
dan mampu bersaing secara global.

Salah satu komoditas yang menunjukkan hasil budaya bangsa adalah tenun tradisional. Pertenunan Santa Maria Boro berdiri tahun 1927 [2]. Jika dilihat dari proses berdirinya Pertenunan Santa Maria Boro, yang dirilis oleh

$\mathrm{Rm}$ JB Prenthaler SJ bertujuan membantu perekonomian warga sekaligus menggeliatkan roda perindustrian di daerah tersebut. Hingga pada tahun 1938, misi Rm Prenthaler SJ ini diteruskan oleh Bruder St Perawan Maria Yang Dikandung Nirmala dari Maastricht (FIC) hingga sekaran [3].

Sejak berdirinya hingga saat ini, Pertenunan Santa Maria Boro menggunakan alat produksi alat tenun bukan mesin (ATBM). Adapun hasil produksi dari Pertenunan Santa Maria Borio berupa kain pel, selimut, serbet, sarung, handuk, sprei, sarung bantal, lap tangan, lap piring, dan lainnya. Akhir-akhir ini, pertenunan juga memproduksi baju imam. Semuanya dibuat dari bahan katun.

Penggunaan ATBM membutuhkan kecermatan dan ketelitian dalam mengoperasikannya, namun kualitas produk tersebut sangat bagus dan tahan lama [4]. Di sisi yang lain, penggunaan ATBM menyerap tenaga kerja yang banyak sehingga cocok digunakan sebagai bagian dari program pemerintah untuk mengurangi pengangguran [5]. Terdapat sekitar 80-an ATBM yang masih bisa digunakan, namun kini hanya tinggal 38 yang dioperasikannya, yang lainnya dibiarkan menganggur. Mesin yang menganggur ini bukanlah mesin yang rusak, namun tidak ada tenaga kerja yang mau mengoperasikannya, sebagian besar tenaga kerja yang ada sudah tua sedangkan tenaga kerja yang muda lebih banyak merantau keluar daerah. Bila dilihat dari tenaga kerja yang ada, maka wajar bila dikatakan mitra mengalami produksi yang stagnan bahkan cenderung menurun karena tidak berani melakukan inovasi baik dari segi pewarnaan maupun dari segi inovasi produksi tenun.

Produksi tenun lurik biasanya dijadikan produk selimut, serbet makan, handuk, sprei, dan beberapa diantaranya bisa dilakukan inovasi [6] dengan diproduksi menjadi tas dengan desain yang sederhana. Kreativitas yang masih rendah ini terjadi karena tidak adanya kemahiran profesional tertentu, semuanya dikerjakan secara otodidak. Bila dilihat dari kualitas produk, tenun lurik Boro bisa dikatakan bagus kualitasnya karena mengandung katun murni [2], namun ketidakmampuan melakukan inovasi produksi dan inovasi pewarnaan membuat produk tersebut kurang diminati masyarakat. Hal ini menjadi wajar, karena mayoritas pekerja tenun Santa Maria Boro berasal dari daerah sekitar Boro dan sebagian besar pekerja melakukannya secara turun temurun.

Kemampuan manajemenpun dirasa kurang baik, hal ini terlihat dari kurangnya kemampuan manajerial dalam melakukan treatment kolaborasi warna, pengambilan resiko rendah dan kemampuan manajerial pemasaran yang belum memadai. Pemasaran selama ini dilakukan dengan cara pemasaran manual, tidak menggunakan metoda pemasaran online, sehingga masyarakat kurang mengenal produk tenun Boro tersebut [7].

Nilai budaya dan kearifan lokal yang nampak dari tenun lurik ini sangat disayangkan apabila akan hilang tergerus oleh arus modernisasi. Menyikapi program pemerintah mengenai industri kreatif, kerajinan tenun lurik ini perlu diperhatikan dan diupayakan inovasinya. Untuk itulah perlu adanya peran serta lembaga pendidikan dan pemerintah untuk melestarikan dan menguatkan nilai budaya tersebut.

Mitra dalam program pengabdian masyarakat ini mengalami kesulitan dalam pewarnaan. Selama ini pewarnaan hanya menggunakan warna dasar misalnya Merah, kuning dan hijau, putih dan hitam. Perpaduan diantara warna-warna tersebut belum berani dilakukan. Demikian juga dengan produksinya, masih baru dibuat sebatas tas dengan desain yang sederhana dan mitra masih sangat tergantung dengan matahari untuk mengeringkan benang, hal ini menimbulkan kecemasan tersendiri saat musim hujan. Bila benang tidak kering, tidak berani untuk dipintal karena kemungkinan saat pemintalan akan banyak benang yang patah.

Program pengabdian ini akan dilakukan dengan terlebih dahulu melakukan inovasi pewarnaan dengan lebih menekankan pada kombinasi pewarnaan dan teknik ikat, [8] dan [9] teknik jepit dan teknik jelujur. Kolaborasi warna akan dilakukan oleh tim pengabdi dengan mencampurkan warna- warna dasar tersebut [10]. Setelah didapatkan kain tenun, inovasi dan kreatifitas produksi dilakukan dan menghasilkan desain produk. Desain produk akan diuji sehingga mampu menghasilkan prototype.

\section{METODE PELAKSANAAN}

Kegiatan pengabdian kreativitas pengolahan limbah dan inovasi pewarnaan kain Tenun Tradisional Santa Maria Boro dilakukan melalui tiga tahapan:

1. Pengedukasian mengenai kolaborasi pewarnaan Pada tahap ini dilakukan pengenalan akan warna dasar dan kombinasi dari warna dasar dengan perpaduan 50:50

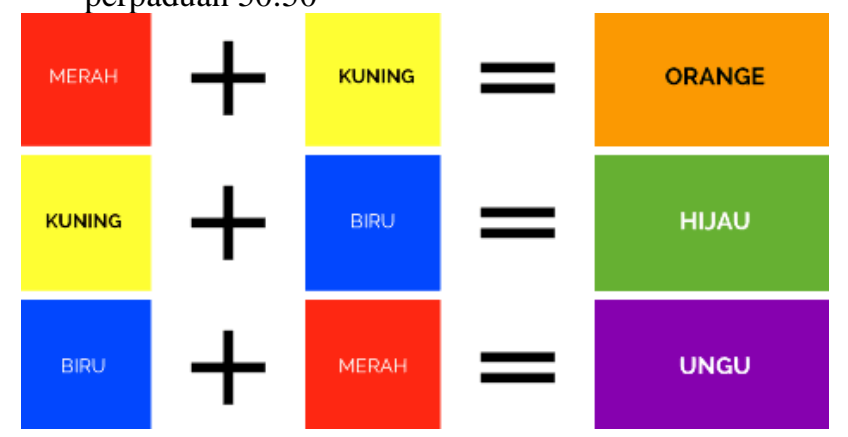


Gambar 1. Kombinasi pewarnaan

2. Pelatihan kolaborasi pewarnaan dengan menggunakan Teknik ikat

a. Persiapan bahan

1) Siapkan kain yang akan diwarnai disertai dengan motif yang diinginkan

2) Panaskan air, masukkan pewarna 1, larutkan

3) Larutkan pewarna 1 dalam air dingin

4) Siapkan air biasa untuk membilas

5) Panaskan air, masukkan pewarna 2, larutkan

6) Larutkan pewarna 2 dalam air dingin

7) Siapkan air biasa untuk membilas

8) Panaskan air, masukkan pewarna 3, larutkan

9) Larutkan pewarna 3 dalam air dingin

10) Siapkan air biasa untuk membilas

b. Teknik inovasi

Tentukan dan buat pola pada kain dengan menggunakan Teknik ikat atau jepit atau kombinasi keduanya.

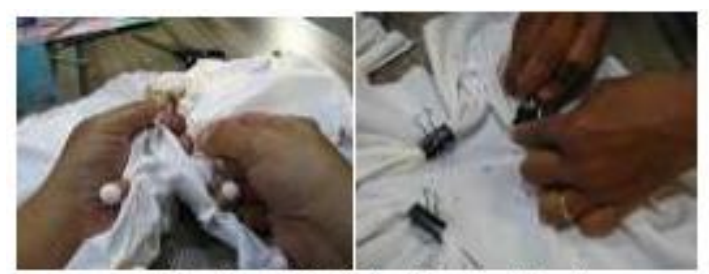

Gambar 2 Teknik ikat dan teknik jepit

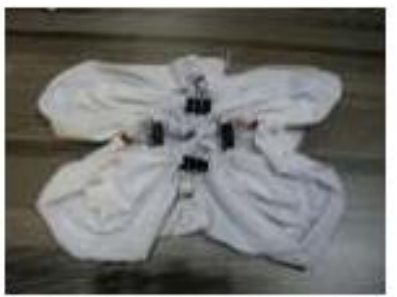

Gambar 3. Kombinasi Teknik ikat dan Telonikjepit

c. Teknik pewarnaan kain hasil inovasi

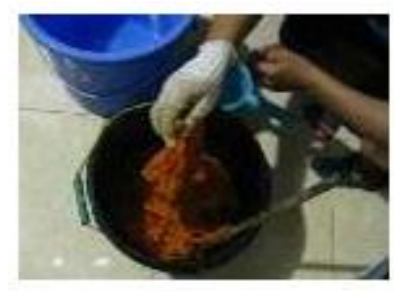

Gambar 4. Telonik pewamaan langkah 1

(1) Masukkan kain dengan Telnik ikat atau Teknik jepit yang akan diwamai kedalam larutan panas

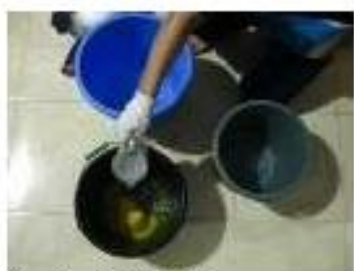

Gambar 6. Teknik pewamaan langkah 3

(3) Masukkan ke air dingin

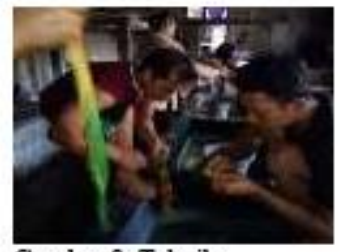

Gambar 8. Telnik pewarnaan langkah ke-5

(5) Menggunakan wama kedua dengan mengikuti tahapan 1-4

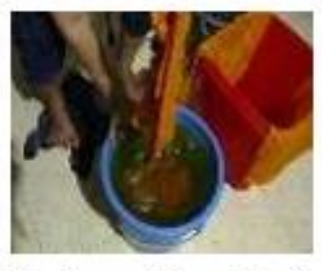

Gambar 7. Telonik pewamaan langkah 4

(4) Bilas dengan air biasa

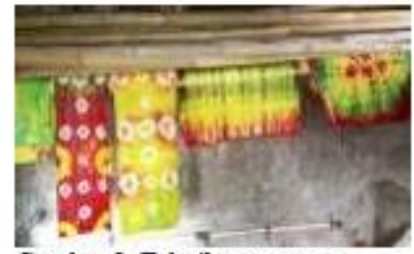

Gambar 9. Telnnik pewarnaan langkah ke-6

(6) Hasil pewamaan dengan teknik Jepit dan teknikikat

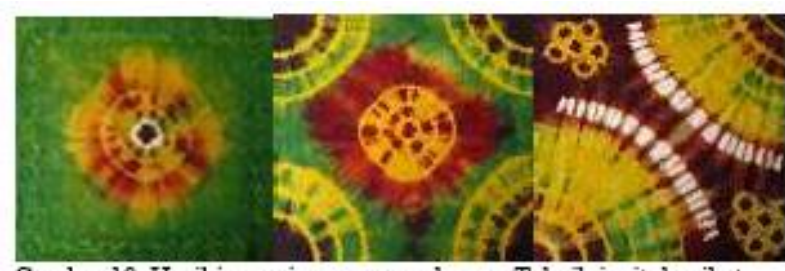

Gambar 10. Hasil inovasi pewarnaan dengan Telonik jepit dan ikat

3. Pemanfaatan limbah kain tenun

Limbah dari kain tenun seringkali disebut sebagai kawul. Kawul ini berasal dari bahan sisa kapas yang masih menempel pada kain dan juga benang yang disortir pada kain yang dipintal. 


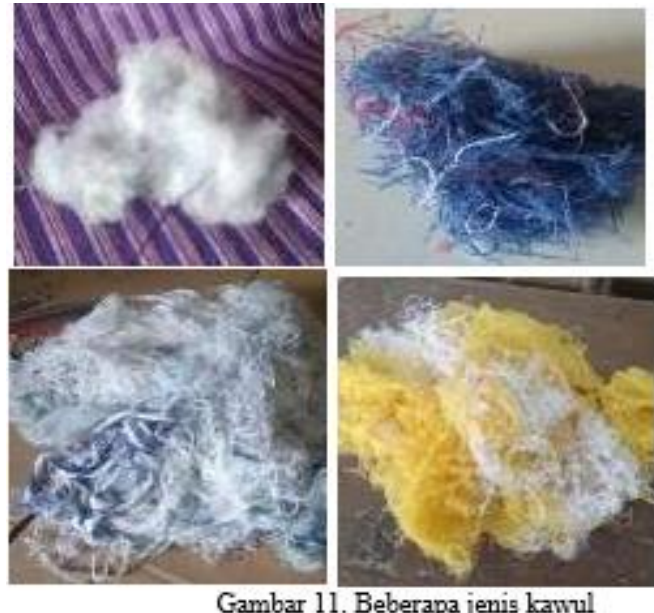

Kawul ini digunakan untuk bahan pengisi souvenir atau boneka kecil yang dijadikan gantungan kunci.

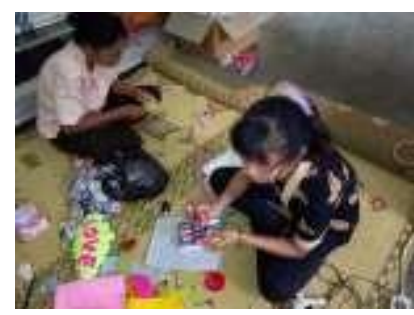

Gambar 12. Kegiatan

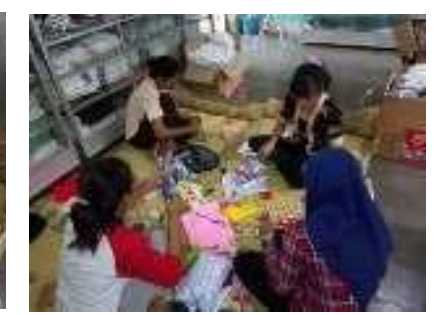

penggunaan dimanfaatkan sebagai isi boneka/ souvenir

\section{DISKUSI}

Saat program ini diajukan, Br Petrus FIC sebagai penanggungjawab dari Pertenunan Santa Maria Boro ini menyambut dengan antusias. Hal ini terlihat dari antusiasme mitra yang menyediakan waktu di luar jam kerja untuk mengikuti program pendampingan masyarakat ini.

Pelaksanaan program ini dibagi menjadi dua kelompok. Kelompok pertama adalah kelompok pekerja laki-laki yang bertugas untuk melakukan kombinasi pewarnaan benang pakan dan benang lungsi. Sementara itu kelompok kedua adalah pegawai wanita yang memiliki bertugas di bagian depan/ front office/ penjahit.

Kelompok pertama, didampingi oleh Ibu Flori dari Akademi Kesejahteraan Sosial AKK dalam pembuatan prototype pewarnaan dikombinasikan dengan Teknik ikat dan Teknik jepit. Mitra dalam kelompok pertama ini terdiri dari 3 orang pegawai laki-laki. Tahap pertama, dilakukan pendampingan pewarnaan. Pertama kali, mitra dikenalkan dengan warna dasar dan kombinasi yang dihasilkan dengan mencampurkan warna dasar tersebut sehingga menghasilkan warna sekunder dan tersier. Ketika didampingi dalam Teknik pewarnaan mitra mengakui adanya perbedaan dan warna yang timbul berbeda dengan yang dihasilkan oleh mereka. Hal ini menimbulkan kegembiran yang terpancar dari wajah para peserta ketika proses pewarnaan dilaksanakan.

Antusiasme dan kegembiraan mitra terlihat ketika tim pengabdi mengajarkan Teknik ikat dan Teknik jepit. Kendati mitra mengakui bahwa program ini adalah program yang pertama kalinya mereka ikuti, mereka juga mengalami kesulitan tersendiri ketika belum menemukan/ mempunyai imajinasi dalam menentukan pola yang akan digunakan. Tahap pembentukan pola, didampingi oleh Ibu Ika dari UKDW. Awalnya, diperkenalkan terdapat tiga pola, yani pola ikat, pola jepit dan pola jelujur. Dalam pelaksanaannya, pola jelujur tidak jadi dilaksanakan dikarenakan mitra enggan dan merasa keberatan. Hal ini wajar, karena mitra yang mengikuti kegiatan pewarnaan adalah kaum laki-laki.

Pola ikat dan pola jepit lebih disukai karena lebih mudah untuk dilakukan. Untuk Teknik ikat, tim pengabdi menggunakan bahan kacang hijau dan karet/ tali raffia untuk mengikatnya. Sedangkan unttuk Teknik jepit, tim pengabdi hanya membutuhkan blinder clip yang ukuran besar-kecilnya menyesuaikan dengan kebutuhan. Penggunaan Teknik ikat dan Teknik jepit ini membutuhkan imajinasi untuk membuat pola. Pola ini perlu dibuat terlebih dahulu untuk agar hasil Teknik ikat dan jepit terlihat simetris. Hal ini menimbulkan kesulitan tersendiri dari pihak mitra, dikarenakan selama ini mewarnai kain jadi bukan menjadi pekerjaan utama mereka.

Sementara itu di kelompok kedua, pemanfaatan kawul yang awalnya hanyalah limbah tidak berguna dan dibuang, kini digunakan sebagai sebagai dasar pengganti dacron untuk membuat souvenir dan gantungan kunci. Penggunaan kawul memiliki kelemahan. Kelemahan pertama, kawul yang berupa benang harus dalam kondisi kering, karena harus dimasukkan ke dalam kain flannel. Ketika kawul dalam kondisi basah maka kemungkinan timbulnya jamur akan cepat terjadi. Namun, hal ini dapat diantisipasi dengan memasukkan beberapa silica gel pada kawul untuk menyerap air dan menghindari tumbuhnya jamur. Mitra cukup senang ketika diajarkan cara membuat souvenir/ gantungan kunci.

Kedua program ini tidak mudah untuk 
dilaksanakan mengingat keterbatasan SDM. Diperlukan kreativitas dan daya imajinasi serta kemauan untuk belajar. Hal ini didukung oleh $\mathrm{Br}$ Petrus FIC selaku pengelola tenun untuk memberikan motivasi dan kesemppatan pada para pegawainya untuk mencari terobosan dan berkreasi. Selaku pimpinan, $\mathrm{Br}$ Petrus FIC meminta untuk sering diadakan program pendampingan agar tenun tradisional mampu bertahan di tengah globalisasi.

\section{KESIMPULAN}

Kreativitas dan inovasi menjadi kata kunci utama untuk terus bertahan di era persaingan global ini. Penciptaan kreasi dan inovasi juga memerlukan kerjasama antara sektor usaha dan dunia pendidikan. Kreativitas perlu diasah dan terus dilaksanakan agar mampu menciptakan keuanggulan kompetitif. Pertenunan Santa Maria Boro sebagai usaha tradisional kendati kualitas barang bagus, namun jika tanpa ditunjang kreativitas dan inovasi, akan tergerus oleh persaingan dunia usaha. Kendati telah tercipta kerjasama antara dunia pendidian dengan dunia usaha, tanpa keberlanjutan, maka usaha ini akan sia-sia. Hal ini juga dapat dikatakan bahwa pelatihan kreasi dan inovasi baik dari segi pewarnaan maupun Teknik hias dalam pewarnaan perlu dilakukan secara terus menerus. Program pengolahan limbah kawul juga perlu dilakukan sebagai upaya untuk mengurangi sampah industry sekaligus untuk meningkatkan nilai tambah suatu produk. Keuletan dan kegigihan memegang perana utama dalam upaya penciptaaan kreativitas dan inovasi menuju proses bisnis berkelanjutan.
Ucapan terimakasih atas bantuan dan kerjasama dari LPPM UKDW dan juga pihak Pertenunan Santa Maria Boro yang berkontribusi dalam program pelatiahn keeativitas dan inovasi produk Pertenunan Santa Maria Boro serta pengolahan limbah Tenun.

\section{DAFTAR PUSTAKA}

[1] B. E. K. \&. B. P. Statistik, "Profil Usaha/ perusahaan 16 subsektor ekraf berdasarkan sensus ekonomi 2016," Badan Pusat statistik, 2016.

[2] "https://www.hidupkatolik.com/2018/04/04/19753/pertenunansanta-maria-boro-pertenunan-di-lereng-menoreh.php," Pertenunan Santa Maria Boro, 04 April 2018. [Online]. [Accessed 25 Agustus 2021].

[3] https://www.jurugan.web.id/2018/01/pertenunan-santa-mariaboro.html, perteunaan santa maria boro, januari 2018. [Online] [Accessed 25 Agustus 2021].

[4] L. S. A. d. S. I. Astuti, Perpustakaan FIS UNY, 2017. [Online]. Available:

http://library.fis.uny.ac.id/opac/index.php?p=show_detail\&id=7587 . [Accessed 25 Agustus 2021].

[5] M. N, “Dinamika Pasar Tenaga Kerja Indonesia (Vol. 1). UMMPress.," UMM Press, vol. 1, 2018.

[6] H. Setiawan, "pengaruh orientasi pasar, orientasi teknologi dan inovasi produk terhadap keunggulan bersaing usaha songket skala kecil di kota Palembang.," Jurnal Orasi Bisnis, vol. 8, no. 2, pp. 1219, 2012.

[7] T. S. I. G. \&. A. M. D. Nurmeisarah, "Tinjauan Tentang Tenun Tradisional Dusun Sade Desa Rambitan Kecamaatan Pujut Kabupaten Lombok Tengah.," E Journal, vol. X, 2015.

[8] A. Salsabila, "Pemanfaatan Teknik Lipat-Ikat Celup untuk Menghasilkan Tekstur pada Kain Busana.," Journal Proceding of Art Design, vol. 4, no. 1, pp. 60-77, 2017.

[9] W. Y. d. Musdalifah, "Kelayakan Produk Tss dengan Pengaplikasian Taktil Teknik Ikat Celup," Fashion and Fashion Education Journal, vol. 9, no. 1, pp. 78-82, 2020.

[10] A. A. Said, Dasar Desain Dwimatra, Badan Penerbit UNM, 2006.

\section{UCAPAN TERIMA KASIH}

